There is a particularly interesting section on the modern research on sharks which is being carried out in laboratories in the United States. The fourth part will be of particular interest to the naturalist, for it gives an excellent account of the shark group as a whole, including the related rays and skates. Finally there is even a section on Selechian cookery.

H. GWYNNE VEVERS

\title{
Birds of Prey, by Philip Brown. Deutsch, 22s. 6d.
}

Less than two years ago a chemical firm sent me copies of a glossy magazine, the not very subtle purpose of which was to publish a review of a certain Miss Rachael Carson's book. The eminent reviewer was scathing. I mention this public relations stunt because the caption to a photograph of a golden eagle stated that it is "no longer a vanishing species". Indeed ?

Philip Brown, writing in 1964, takes a less sanguine view. "So far as birds of prey are concerned, there is now no certainty at all that we shall be able to continue to enjoy them." And the blame for this state of affairs he is not afraid to apportion : "We can blame the Government and the vested interests who manufacture death, often indiscriminately, on a scale almost beyond the liveliest imagination, but in the event it all comes down to what the individual is prepared to tolerate". The Government's technical advisers and the vested interests escape the indictment lightly; Philip Brown addresses himself to the "individual ".

This is a popular account of the "hawks" and owls of Britain, the first volume in a series called "Survival Books", with the dodo as its emblem. We need not expect the authors, writing under the symbol for the deadest of the dead, to pull their punches. Philip Brown hits out with accuracy and angry purpose. If these Survival Books follow this splendid beginning and come in time to influence events-and not merely to chronicle extinctionthey are to be warmly welcomed.

G. DES FORGES

\section{Predators and Anti-predator Behaviour of the Black-headed Gull, by} Hans Kruuk. E. J. Brill, Leiden, 36 guilders.

Dr. Kruuk's study of the black-headed gull colony at Ravenglass in Cumberland, where so much valuable work on behaviour has been done by Dr. N. Tinbergen and his co-workers, sprang partly from the only too obvious and disturbing predation by foxes upon the gulls-in 1962 the local foxes killed 825 adults ( 230 in one night) and 1,100 young gulls-and was extended to examine all predators concerned (other gulls, crows, birds of prey, stoats, hedgehogs, the black-headed gull itself) and some other prey species. His approach was primarily that of an ethologist, and the wealth of observation and experiment, especially the inferences from the scrutiny of tracks in this sandy area is characteristic of the keen and patient naturalist. Some of the results, with their recurring tables and statistical tests, will be rather hard going for the ordinary naturalist but this is the way in which ethologists work nowadays.

The main conclusions, based on a careful accumulation of data and on probing experiments, suggest that the black-headed gull's reactions to predators range from simple escape through social mobbing to direct attack, and that the part of this range used against any specific predator depends upon a number of variable factors, important among which are whether the predation is directed towards young or adults and whether the predator is in the air or on the ground. Dr. Kruuk concludes that the Ravenglass colony, 